\title{
Tannic acid-modified silver nanoparticles for wound healing: the importance of size
}

This article was published in the following Dove Press journal: International Journal of Nanomedicine

\author{
Piotr Orlowski ${ }^{1}$ \\ Magdalena Zmigrodzka ${ }^{2}$ \\ Emilia Tomaszewska ${ }^{3}$ \\ Katarzyna Ranoszek- \\ Soliwoda ${ }^{3}$ \\ Monika Czupryn' \\ Malgorzata Antos-Bielska' \\ Janusz Szemraj ${ }^{4}$ \\ Grzegorz Celichowski ${ }^{3}$ \\ Jaroslaw Grobelny ${ }^{3}$ \\ Malgorzata Krzyzowska' \\ 'Military Institute of Hygiene and \\ Epidemiology, Warsaw, Poland; \\ ${ }^{2}$ Department of Pathology and \\ Veterinary Diagnostics, Faculty \\ of Veterinary Medicine, Warsaw \\ University of Life Sciences (WULS- \\ SGGW), Warsaw, Poland; ${ }^{3}$ Department \\ of Materials Technology and \\ Chemistry, Faculty of Chemistry, \\ University of Lodz, Lodz, Poland; \\ ${ }^{4}$ Bionanopark, Lodz, Poland
}

Correspondence: Malgorzata Krzyzowska Military Institute of Hygiene and Epidemiology, ul Kozielska 4, 0I-163 Warsaw, Poland

Tel +48 606223464

Fax +48226122718

Email krzyzowskam@yahoo.com
Introduction: Silver nanoparticles (AgNPs) have been shown to promote wound healing and to exhibit antimicrobial properties against a broad range of bacteria. In our previous study, we prepared tannic acid (TA)-modified AgNPs showing a good toxicological profile and immunomodulatory properties useful for potential dermal applications.

Methods: In this study, in vitro scratch assay, antimicrobial tests, modified lymph node assay as well as a mouse splint wound model were used to access the wound healing potential of TA-modified and unmodified AgNPs.

Results: TA-modified but not unmodified AgNPs exhibited effective antibacterial activity against Pseudomonas aeruginosa, Staphylococcus aureus and Escherichia coli and stimulated migration of keratinocytes in vitro. The tests using the mouse splint wound model showed that TA-modified 33 and $46 \mathrm{~nm}$ AgNPs promoted better wound closure, epithelialization, angiogenesis and formation of the granulation tissue. Additionally, AgNPs elicited expression of VEGF- $\alpha$, PDGF- $\beta$ and TGF- $\beta 1$ cytokines involved in wound healing more efficiently in comparison to control and TA-treated wounds. However, both the lymph node assay and the wound model showed that TA-modified AgNPs sized $13 \mathrm{~nm}$ can elicit strong inflammatory response not only during wound healing but also when applied to the damaged skin.

Conclusion: TA-modified AgNPs sized $>26 \mathrm{~nm}$ promote wound healing better than TAmodified or unmodified AgNPs. These findings suggest that TA-modified AgNPs sized $>26 \mathrm{~nm}$ may have a promising application in wound management.

Keywords: hydrolyzable tannin, split wound, silver, antimicrobials, inflammation, fibroblasts, monocytes

\section{Introduction}

Skin wound healing is a complex process involving 3 stages that overlap in time and space: inflammation, new tissue formation (granulation and angiogenesis) and tissue remodeling. ${ }^{1}$ These 3 phases involve well-organized interactions between various cell types such as leukocytes, fibroblasts and keratinocytes and are controlled by several factors, including cytokines, chemokines, growth factors and enzymes. ${ }^{1,2}$ Following the initial hemostasis, inflammation is a critical part of the normal wound healing process. Prolonged inflammation hampers entering into the proliferative phase and delays wound closure. Chronic wounds represent a major health burden and remain a challenging clinical problem. Therefore, many studies have focused on the principles and mechanisms of wound healing acceleration to develop new drugs and/or dressings that promote wound healing. ${ }^{3,4}$

The importance of silver as an antimicrobial agent has been known for centuries, and its use has recently increased with the development of silver nanoparticles (AgNPs). ${ }^{5}$ AgNPs have a large surface area, resulting in large amounts of silver ions 
being released and potentially penetrating into the skin, particularly the damaged skin. ${ }^{6}$ There are numerous reports indicating that AgNPs promote wound healing and show antimicrobial properties against a broad range of bacteria, including Pseudomonas aeruginosa, Escherichia coli and Staphylococcus aureus..$^{7,8}$ Wound dressings containing AgNPs have also been suggested to enhance wound healing by decreasing the inflammatory response. ${ }^{9,10}$

Tannins are plant phenol derivatives of various molecular weights naturally synthesized by plants as metabolic products. ${ }^{11-13}$ Tannic acid (TA, penta-m-digalloyl glucose) is the simplest and principal hydrolyzable tannin that has astringent, antioxidant, antimicrobial, antiviral and antiinflammatory properties. ${ }^{14,15}$ Structurally, TA has a glucose moiety as a core and the hydroxyl groups of glucose are esterified with 5 digallic acids. ${ }^{15}$ Although tannin extracts have been used to improve the process of wound healing for many years, their exact mechanism of action has not been completely elucidated to date. It is believed that tannins can promote wound healing through several mechanisms: 1) scavenging of free radicals and reactive oxygen species (ROS), 2) promoting wound contraction, and 3) increasing formation of capillary vessels and proliferation of fibroblasts. ${ }^{12-14}$

Synthesis of AgNPs with plant extracts is known as the green synthesis, which is believed to be eco-friendly. TA is an effective reducing and stabilizing agent, which allows us to obtain AgNPs with homogeneous spherical shape and a narrow size distribution. ${ }^{16}$ Moreover, synthesis of AgNPs with TA is more stable compared with other methods. ${ }^{17}$

In our previous studies, we demonstrated that toxicity of TA-modified AgNPs was cell-type dependent, with monocytes but not keratinocytes, producing ROS when exposed to AgNPs. ${ }^{18,19}$ Furthermore, TA-modified AgNPs sized $>30 \mathrm{~nm}$ showed a good toxicological profile in vitro in human HaCaT and VK2-E6/E7keratinocyte cell lines and possessed immunomodulatory properties useful for potential dermal applications in humans. ${ }^{19}$ TA-modified but not unmodified AgNPs downregulated tumor necrosis factor- $\alpha$ (TNF- $\alpha$ )- and lipopolysaccharide (LPS)-triggered production of interleukin 8 (IL-8) in VK2-E6/E7 cells. ${ }^{19}$

In this study, the wound healing potential of TA-modified AgNPs was tested. The cytotoxicity and antibacterial activity in vitro, as well as the effect on wound healing in vitro and in vivo of TA-modified AgNPs, were evaluated. It is hypothesized that TA modification can promote wound healing by influencing inflammatory reaction and exerting antimicrobial properties. The importance of nanoparticle size in the wound healing process is also shown.

\section{Materials and methods Synthesis of AgNPs}

TA-modified (the size of metallic core: 13, 33 and $46 \mathrm{~nm}$ ) and unmodified AgNPs (10-65 nm) were synthesized as described previously via the chemical reduction method in water. ${ }^{16,18-20}$ Briefly, AgNP colloids sized 13, 33 and $46 \mathrm{~nm}$ were synthesized with silver nitrate and the mixture of sodium citrate and TA. In our previous study, we showed the crucial role of this mixture in the synthesis of monodisperse AgNPs compared to the synthesis carried out with sodium citrate or TA alone. ${ }^{16}$ Only the combined use of citrate and TA produced an active CA-TA complex, which enabled control of the reaction conditions resulting in homogeneous size and shape of AgNPs. A colloid with a broad range of particle sizes (10-65 nm) was synthesized with only sodium citrate, and constitutes the unmodified AgNPs (the synthesis carried out without TA). This colloid was used in our biological experiments as a reference sample, since it contains particles with the sizes within the range of tested colloids. Nanoparticles were characterized for shape, size and size distribution after each synthesis by dynamic light scattering (DLS) and transmission electron microscopy (TEM), as described previously. ${ }^{18}$ The colloidal stability was analyzed with ultraviolet-visible (UV-vis) spectroscopy and through zeta potential measurements.

\section{Cell culture and treatment}

Mouse L929 fibroblasts from American Type Culture Collection (ATCC CCL-1; Manassas, MD, USA) were propagated in Eagle's Minimum Essential Medium (MEM) supplemented with $10 \%$ fetal calf serum, $10 \mathrm{U} / \mathrm{mL}$ penicillin and $100 \mu \mathrm{g} / \mathrm{mL}$ streptomycin (Thermo Fisher Scientific, Waltham, MA, USA). Mouse RAW 264.7 monocytes (ATCC TIB-71) were maintained in RPMI-1640 medium with 10\% fetal bovine serum (FBS) and 1\% antibiotics (Thermo Fisher Scientific). Human HaCaT keratinocytes were obtained from the Department of Clinical Virology, University of Gothenburg, Göteborg, Sweden and propagated in DMEM supplemented with $10 \%$ fetal calf serum, $10 \mathrm{U} / \mathrm{mL}$ penicillin and $100 \mu \mathrm{g} / \mathrm{mL}$ streptomycin (Thermo Fisher Scientific). The cells were seeded into 24 -well plates at the density of $5 \times 10^{4} / \mathrm{mL}$ cells and cultured for $48 \mathrm{~h}$ before exposure to nanoparticles at the concentration range of $0.5-10 \mu \mathrm{g} / \mathrm{mL}$. After another $24 \mathrm{~h}$, fresh medium was applied, and the cells were used for further analyses.

\section{Visualization of AgNPs}

For microscopy detection of nanoparticles, cells were plated on Lab-tek II chamber slides (Nunc; Thermo Fisher Scientific) 
at a density of $1 \times 10^{5} / \mathrm{mL}$ for $18 \mathrm{~h}$ before exposure to nanoparticles. After $24 \mathrm{~h}$ of exposure to $5 \mu \mathrm{g} / \mathrm{mL}$ of AgNPs, the medium was discarded, and the cells were fixed with $4 \%$ paraformaldehyde (PFA) in PBS, washed twice with PBS and covered with PBS containing $2 \mu \mathrm{g} / \mathrm{mL}$ Hoechst 33342 (Sigma-Aldrich Co., St Louis, MO, USA). The images were captured with the DMi8 inverted microscope with MC170HD camera coupled with the laser scan confocal system TCS SP8 (Leica Microsystems, Wetzlar, Germany). Bidirectional scan was performed with the acquisition speed of $200 \mathrm{~Hz}$. Images were acquired in $Z$ axis using water objective CS2 of magnification $63 \times$ and digital zoom $1.5 \times$. Due to the signal interference, sequential scanning was applied to all samples. The obtained images were analyzed in Leica Application Software X (LAS X) Version 2.0.

\section{Toxicity tests}

Toxicity of AgNPs was accessed using Annexin V-Apoptosis detection kit I (BD Biosciences, San Jose, CA, USA), according to the manufacturer's protocol. The annexin V-positive, propidium iodide (PI)-negative cells were scored as apoptotic cells, while all PI-positive cells were considered to be necrotic. Changes in the mitochondrial potential were measured in cells stained with a cationic dye, 5,5',6,6'tetrachloro 1,1',3,3'-tetraethyl-benzimidazolylcarbocyanine iodide (JC-1) (Sigma-Aldrich), as described previously. ${ }^{18,19,21}$ The stained cells were analyzed in FACSCalibur using CellQuest program (BD Biosciences). Neutral red uptake assay was performed as described previously. ${ }^{18}$ The viability of the cells was expressed as a percentage of the control, untreated cells $(100 \%) .^{18,19}$

\section{Antibacterial assays}

S. aureus ATCC 25923, P. aeruginosa ATCC 27853 and E. coli ATCC 15597 were used to determine the antibacterial activities of AgNPs. Minimum inhibitory concentrations (MICs) were determined in Mueller-Hinton broth (MHB) medium using a serial dilution method. Test tubes containing 2-fold dilutions of AgNPs in concentrations ranging from 0.78 to $50 \mu \mathrm{g} / \mathrm{mL}$ were inoculated with bacterial suspension to yield the appropriate density $\left(10^{5} \mathrm{CFU} / \mathrm{mL}\right)$ and incubated for $18-20 \mathrm{~h}$ at $37^{\circ} \mathrm{C}$. The MIC was defined as the lowest concentration of the silver additive at which no visual turbidity of the growth medium developed. All measurements of MIC values were repeated in triplicate.

\section{Wound assay in vitro}

$\mathrm{HaCaT}$ cells were plated in 24-well dishes and cultured to $100 \%$ confluence. Scratches were produced using $200 \mu \mathrm{L}$ pipette tips, as described by Liang et al. ${ }^{22}$ After washing, the cells were treated with medium containing AgNPs at $5 \mu \mathrm{g} / \mathrm{mL}$. After $24 \mathrm{~h}$ treatment, the cells were fixed with 4\% PFA buffered with phosphate-buffered saline (Avantor, Gliwice, Poland) and stained with crystal violet. Microphotographs were taken using a Zeiss Axiovert A1 (Zeiss, Oberkochen, Germany) inverted microscope using $5 \times$ objective and analyzed with ImageJ software.

\section{Ethical statement}

This study was performed in strict accordance with the recommendations of the Polish Act of 21 January 2005 on animal experiments (OJ no 33, item 289) and Directive 2010/63/EU of the European Parliament and the Council of 22 September 2010 on the protection of animals used for scientific purposes. The protocol was approved by the 4th Local Committee on the Ethics of Animal Experiments in Warsaw, Poland (permit number: 58/2013 and 76/2015). The use of $\mathrm{HaCaT}$ cell line was approved by the Scientific Board of the Military Institute of Hygiene and Epidemiology as part of the PhD thesis of Piotr Orłowski (December 2014).

\section{Local lymph node assay (LLNA)}

Female C57BL6 mice (Mossakowski Medical Research Centre, Warsaw, Poland), 7 weeks of age, were assigned to groups ( 3 animals per group) using a stratified random grouping method based on individual body weights. Ears were stripped 10 times with an ordinary adhesive tape (Polopor, Viscoplast; Polfa Warszawa, Poland). For each stripping, a fresh piece of tape was lightly pressed onto the ear and pulled off. After tape stripping, vehicle (acetone: olive oil, 3:1) negative control, $25 \% \mathrm{w} / \mathrm{v}$ citral in vehicle (Sigma-Aldrich) positive control, and $25 \% \mathrm{w} / \mathrm{v}$ of AgNPs in vehicle were applied to the dorsum of each ear $(25 \mu \mathrm{L} /$ ear $)$ once daily for 3 consecutive days (days 1-3). On day 5, the draining auricular lymph nodes from each mouse ear were excised and processed separately in PBS for each animal. Cells were seeded in 96-well round bottom plates at $10^{4}$ cells per well in RPMI medium without phenol red supplemented with $10 \%$ FBS, $10 \mathrm{U} / \mathrm{mL}$ penicillin, $100 \mu \mathrm{g} / \mathrm{mL}$ streptomycin (Thermo Fisher Scientific), $2 \mu \mathrm{g} / \mathrm{mL}$ concanavalin A (Sigma-Aldrich), $10 \%$ resazurin (Thermo Fisher Scientific) and cultured for $72 \mathrm{~h}$. Fluorescence was measured at $540 \mathrm{~nm}$ (emission) and at $600 \mathrm{~nm}$ (reference) using a FLUOstar Omega counter (BMG Labtech, Ortenberg, Germany).

\section{Wound model in vivo}

Female C57BL6 mice (Mossakowski Medical Research Centre, Warsaw, Poland), 7 weeks of age, were assigned 
to groups (5 animals per group), as described earlier. Mice were anesthetized by intraperitoneal injection of $85 \mathrm{mg} / \mathrm{kg}$ ketamine (Biowet, Pulawy, Poland) and $11 \mathrm{mg} / \mathrm{kg}$ xylazine (Xylopan; Polypharm SA, Warsaw, Poland). Hair removal and sterilization were performed routinely. Two full-thickness circular excisions that included the panniculus carnosus on either side of the mouse's midline at the level of the shoulders were created using a sterile $4 \mathrm{~mm}$ biopsy punch (Kruuse, Langeskov, Denmark). Next, a $5 \mathrm{~mm}$ silicone splint (Zegir, Warsaw, Poland) was applied around the excision with a cyanoacrylate adhesive (Super Glue) and anchored with interrupted 6-0 nylon sutures to ensure positioning. AgNPs or TA was applied at $5 \mu \mathrm{g} / \mathrm{mL}$ in saline in the volume of $100 \mu \mathrm{L}$ to 1 wound, and a vehicle control to the other. The wound was covered with a transparent occlusive dressing using incise drape (3M Health Care, Neuss, Germany). A total of $5 \mathrm{mg} / \mathrm{kg}$ of meloxicam (Loxicom; ScanVet, Gniezno, Poland) was administered once daily via subcutaneous injection for post-operative pain relief during the first 3 days. At days 3 , 6 and 14, mice were euthanized, and then the wounds were excised and used for further tests.

\section{Morphological analyses of wound re-epithelialization, inflammatory infiltration and angiogenesis}

Skin specimens were fixed in 4\% PFA buffered with PBS ( $\mathrm{pH} 7.4$ ) and embedded in paraffin. Five micrometer sections were prepared on a microtome. Hematoxylin/eosin and Masson's trichrome stainings were performed according to the manufacturer's instructions (Sigma-Aldrich). The images were captured with the Zeiss Axio Imager.M2 (Zeiss). The wound closure was calculated as percentage of wound area at the time point in comparison to the initial wound area. The epithelial sheet area (re-epithelialization) was measured in the cross sections stained with hematoxylin/eosin. Cell numbers and blood vessels were counted in 5 randomly selected microscope fields per section in the wound cavity at $400 \times$ magnification $\left(0.234 \mathrm{~mm}^{2}\right)$.

\section{Immunohistochemistry}

The tissues were fixed and processed as described earlier. Antigens were unmasked in $0.1 \mathrm{M}$ citrate buffer $(\mathrm{pH}=6.0)$ for $10 \mathrm{~min}$. Macrophages were detected using F4/80 antibody (clone A3-1) (Santa Cruz Biotechnology Inc., Dallas, TX, USA), while neutrophils were detected with anti-Gr-1 antibody (RB6-8C5) (BD Biosciences) in PBS with 1\% bovine serum albumin, followed by $30 \mathrm{~min}$ incubation with biotinylated anti-rat IgG antibody (1:200) (BD Biosciences) and streptavidin peroxidase (BD Biosciences) (1:500) in the same buffer. Sections were developed with 3,3'-diaminobenzidine (DAB) and counterstained with Harris's hematoxylin solution (Sigma-Aldrich). Image capture, analysis and processing were performed using the Zeiss Axio Imager.M2 microscope and ZEN 2011 software (Zeiss). For all stainings, isotype control antibodies (rat monoclonal $\mathrm{IgG}$ ) were used (BD Biosciences).

\section{Quantitative reverse transcription polymerase chain reaction (qRT-PCR)}

Total RNA was isolated from the wound tissues preserved in RNAlater (Sigma-Aldrich) using Universal RNA Purification Kit (Eurx, Gdansk, Poland). cDNA was reverse-transcribed from $1 \mu \mathrm{g}$ of total RNA using High Capacity RNA-to-cDNA Kit (Thermo Fisher Scientific) according to the manufacturer's protocol. Transcripts of IL-1 $\beta$, TNF- $\alpha$, plateletderived growth factor- $\alpha$ (PDGF- $\alpha)$, vascular endothelial growth factor- $\alpha$ (VEGF- $\alpha$ ), transforming growth factor $\beta 1$ (TGF- $\beta 1$ ) and GADPH were quantified using Taqman(R) Gene Expression Assays (Thermo Fisher Scientific). All PCR reactions were carried out with TaqMan Gene Expression Master Mix using 7500 Real Time PCR System (Thermo Fisher Scientific) according to the manufacturer's protocol. The $2 \Delta^{-\mathrm{DCt}}$ method was used for calculating the relative ratio. mRNA levels were counted from 3 PCR reactions for each sample.

\section{Statistical methods}

Data are shown as mean \pm standard error of the mean (SEM) from at least 3 independent experiments. Data were analyzed using a 2-tailed paired Student's $t$-test (normal distribution), or non-parametric Kruskal-Wallis and Wilcoxon tests were applied using SigmaPlot software. In every analysis, $p$-value of $\leq 0.05$ was considered significant.

\section{Results \\ Characterization of AgNPs}

To find a correlation between the NPs size and their biological properties, all AgNPs were precisely characterized using UV-vis spectroscopy, electron microscopy, DLS and zeta potential measurements. UV-vis spectroscopy is a simple, fast and sensitive method for characterization of metallic NPs. The maxima of the adsorption bands of the tested AgNP colloids were detected in the region characteristic for AgNPs at 405, 408, 414 and $430 \mathrm{~nm}$ for Figure 1A-D, respectively. It can be easily seen that the adsorption band maximum shifts to longer wavelengths with the increase in the particle size. 
A

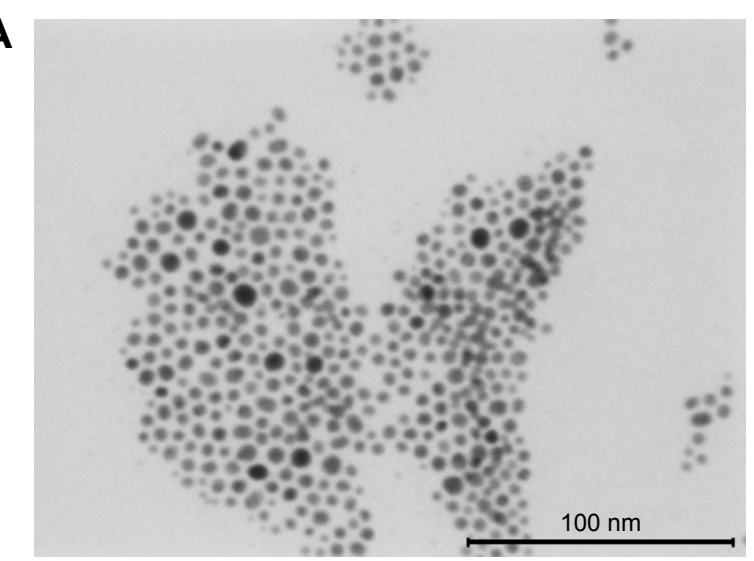

B

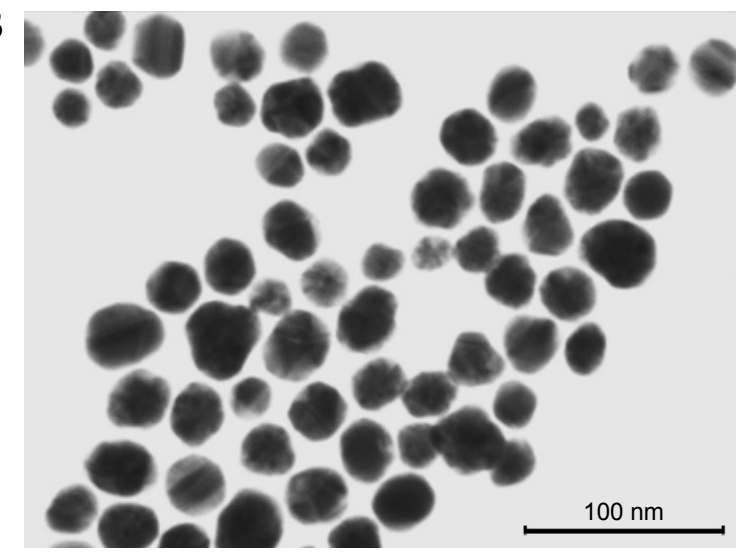

C

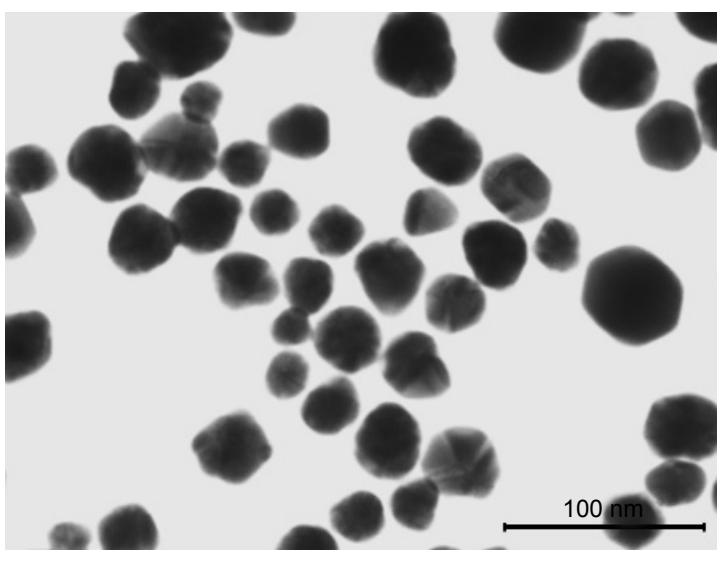

D

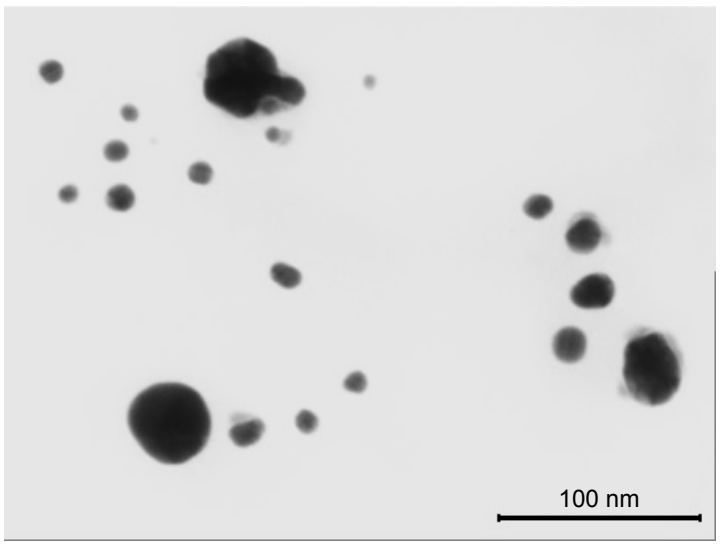

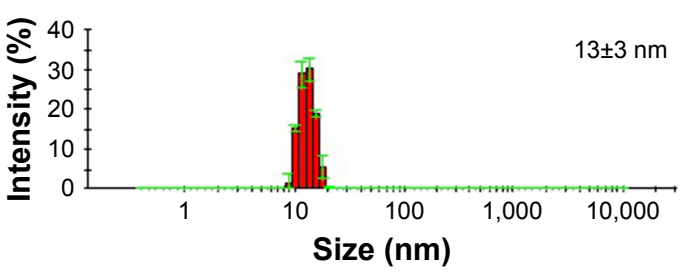
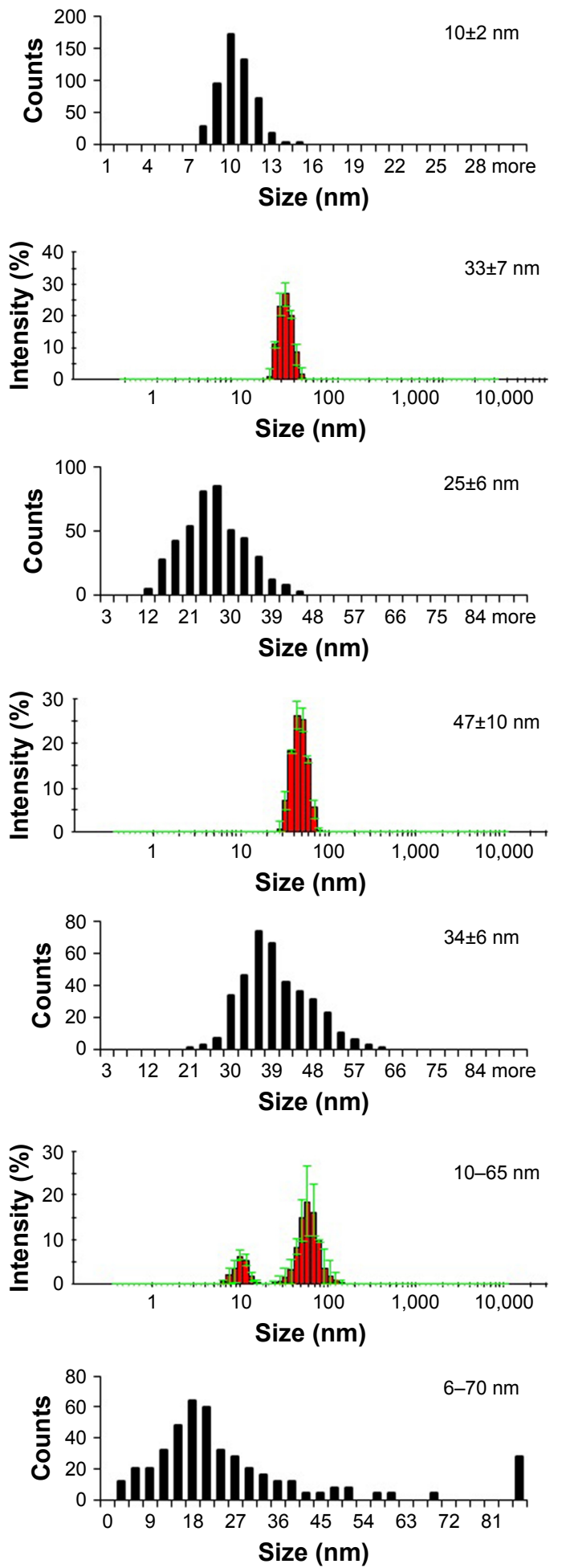

Figure I DLS histograms and STEM images with size distribution histograms of AgNPs (A) TAm- I3, (B) TAm-33, (C) TAm-46 nm AgNPs and (D) UN I0-65 nm AgNPs. Abbreviations: AgNPs, silver nanoparticles; DLS, dynamic light scattering; STEM, scanning transmission electron microscopy; TAm, tannic acid-modified; UN, unmodified. 
The morphology, shape and the mean size of the metallic core of AgNPs were tested using the electron microscopy. Figure 1 shows representative Scanning Transmission Electron Microscopy (STEM) images of AgNPs. STEM images confirm the formation of monocrystalline AgNPs with a regular spherical shape. The mean size of AgNPs metallic core was $10 \pm 2,25 \pm 6,34 \pm 6$ and 6-70 $\mathrm{nm}$ for Figure 1A-D, respectively. Furthermore, all AgNP colloids were tested by the DLS technique for the hydrodynamic size of particles and colloidal stability. The hydrodynamic sizes of particles were as follows: $13 \pm 3 \mathrm{~nm}$ (Figure 1A), 33 $\pm 7 \mathrm{~nm}$ (Figure 1B), $46 \pm 10 \mathrm{~nm}$ (Figure 1C) and 10-65 nm (Figure 1D). All AgNP colloids were stable and any additional signals from larger particles or agglomerates were not observed. However, it is well-known that for DLS measurements, there is a risk that small objects present in the sample can be screened by bigger ones and will not be seen during the measurement. ${ }^{20}$ However, DLS results along with the STEM images allowed us to conclude that the tested colloids were monodisperse.

It is well-known that the charge affects physical stability of nanoparticles in a colloidal solution. The colloidal stability of AgNPs was analyzed through zeta potential measurements which are an indirect measure of the surface charge and allow evaluation of the expected storage stability of a colloidal dispersion (high positive or negative zeta potential values indicate the high stability of colloids). The zeta potentials of the tested samples were as follows: $-31 \pm 7,-58 \pm 2,-55 \pm 2$ and $64 \pm 1 \mathrm{mV}$ for colloids 1, 2, 3 and 4, respectively. These values along with the DLS results confirm the high stability of all investigated colloids.

\section{Antimicrobial activity of modified and unmodified AgNPs}

$P$. aeruginosa and $S$. aureus are the most common bacteria responsible for wound infection. ${ }^{5,6}$ The inhibitory effects of TA-modified AgNPs were size-dependent with $13 \mathrm{~nm}$ AgNPs showing the lowest MIC values $(1.56 \mu \mathrm{g} / \mathrm{mL}$ for S. aureus, $3.13 \mu \mathrm{g} / \mathrm{mL}$ for $P$. aeruginosa and $0.78 \mu \mathrm{g} / \mathrm{mL}$

Table I Antibacterial activities of AgNPs (MIC in $\mu \mathrm{g} / \mathrm{mL}$ ) against 3 pathogenic bacterial strains

\begin{tabular}{llll}
\hline & $\begin{array}{l}\text { Staphylococcus } \\
\text { aureus }\end{array}$ & $\begin{array}{l}\text { Pseudomonas } \\
\text { aeruginosa }\end{array}$ & $\begin{array}{l}\text { Escherichia } \\
\text { coli }\end{array}$ \\
\hline TAm-13 nm & 1.56 & 3.13 & 0.78 \\
TAm-33 nm & 3.13 & 12.5 & 6.25 \\
TAm-46 nm & 3.13 & 12.5 & 6.25 \\
UN 10-65 nm & 6.25 & 25 & 12.5 \\
Tannic acid & $>50$ & $>50$ & $>50$ \\
\hline
\end{tabular}

Abbreviations: AgNPs, silver nanoparticles; MIC, minimal inhibitory concentration; TAm, tannic acid-modified; UN, unmodified. for E. coli) (Table 1). TA-modified 33 and $46 \mathrm{~nm}$ AgNPs showed the same MIC values $(3.13 \mu \mathrm{g} / \mathrm{mL}$ for $S$. aureus, $12.5 \mu \mathrm{g} / \mathrm{mL}$ for $P$. aeruginosa and $6.25 \mu \mathrm{g} / \mathrm{mL}$ for $E$. coli) (Table 1). Unmodified 10-65 nm AgNPs showed the lowest inhibitory activity against $S$. aureus, $P$. aeruginosa and $E$. coli $(>50 \mu \mathrm{g} / \mathrm{mL})$ (Table 1).

\section{Internalization of AgNPs}

Figure 2 shows representative images of RAW 264.7 monocytes (Figure 2A-E) and L929 fibroblasts (Figure 2F-J) with internalized nanoparticles (green fluorescence). Fibroblasts internalized significantly less nanoparticles than monocytes for all types of AgNPs. In both cell types, bigger sizes (33 and $46 \mathrm{~nm}$ TA-modified AgNPs) (Figure 2C and D) were accumulated more than $13 \mathrm{~nm}$ TA-modified AgNPs (Figure 2B). However, L929 fibroblasts accumulated unmodified 10-65 nm AgNPs more efficiently than monocytes (Figure 2J).

\section{Toxicity of TA-modified AgNPs}

As shown in Figure 3A, the cytotoxic effect of AgNPs upon the mitochondrial potential in L929 cells was dose-dependent. Addition of TA, 13, 33, and $46 \mathrm{~nm}$ TA-modified AgNPs at $5 \mu \mathrm{g} / \mathrm{mL}$ to $\mathrm{L} 929$ cell cultures resulted in a significant increase in the percentage of cells with a decreased mitochondrial potential $(19.81 \% \pm 0.53 \%, 29.65 \% \pm 4.87 \%$ and $27.82 \% \pm 3.57 \%$, respectively) ( $p \leq 0.05$ ) (Figure 3A). TA-modified 13, 33 and $46 \mathrm{~nm}$ AgNPs at $10 \mu \mathrm{g} / \mathrm{mL}$ resulted in the further increase in the percentage of cells with a decreased mitochondrial potential ( $p \leq 0.05$ ) (Figure 3A). No significant influence of unmodified 10-65 $\mathrm{nm}$ AgNPs upon the mitochondrial potential in L929 was found (Figure 3A). Effective concentration 50 (EC50) values for unmodified 10-65 $\mathrm{nm}$ AgNPs remained higher in comparison to EC50 values for TA-modified 13, 33 and 46 nm AgNPs as well as TA, and the values were as follows: $39.56 \pm 11.82$ vs $23.96 \pm 3.46$, $13.09 \pm 2.51,12.46 \pm 2.75$ and $11.13 \pm 2.3 \mu \mathrm{g} / \mathrm{mL}$, respectively.

Since a decrease in mitochondrial potential usually precedes induction of apoptosis, we used annexin $\mathrm{V}$ staining to confirm AgNPs toxicity. The results of the annexin V/PI assay showed that only TA-modified $13 \mathrm{~nm}$ AgNPs induced apoptosis in L929 cells at 5 and $10 \mu \mathrm{g} / \mathrm{mL}(p \leq 0.05)$ (Table 2), while only TA-modified 13 and $33 \mathrm{~nm} \mathrm{AgNPs} \mathrm{at}$ $10 \mu \mathrm{g} / \mathrm{mL}$ induced necrosis $(p \leq 0.05)$ (Table 2$)$.

\section{In vitro scratch assay}

Next, we chose to investigate the effect of TA-modified and unmodified AgNPs on the migration of keratinocytes in cell culture. The scratch assay using human $\mathrm{HaCaT}$ cell line is a well-characterized method to measure keratinocyte migration 

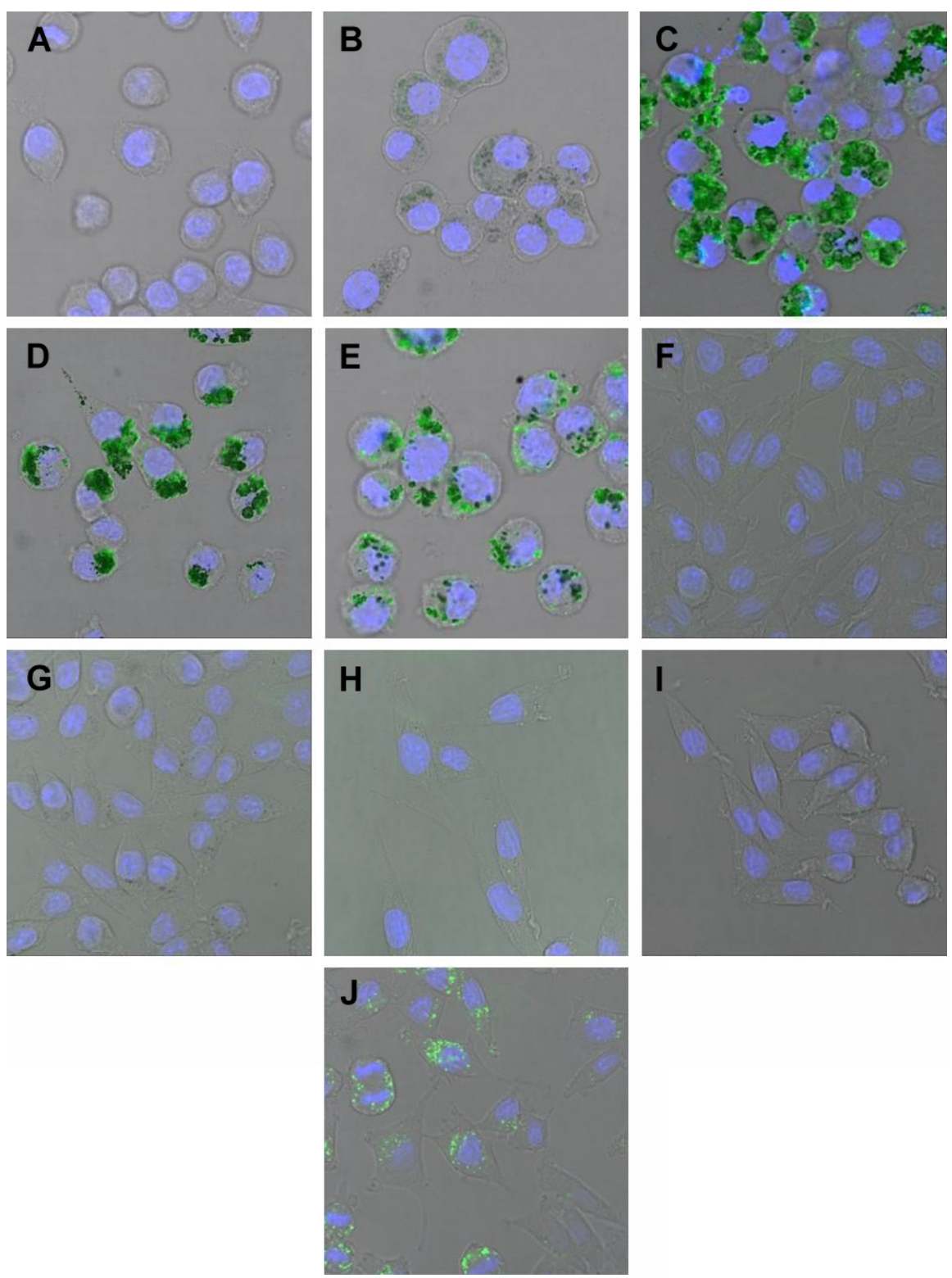

Figure 2 Fibroblasts internalize AgNPs less effectively than monocytes.

Notes: Confocal microscopy images showing TA and unmodified AgNPs inside the cells (green). Nuclei were stained with Hoechst 33342. Images were captured using $63 \times$ objective lens and I.5× digital zoom. (A) RAW control; (B) RAW TAm-13 nm; (C) RAW TAm-33 nm; (D) RAW TAm-46 nm; (E) RAW UN I0-65 nm; (F) L929 control; (G) L929 TAm-13 nm; (H) L929 TAm-33 nm; (I) L929 TAm-46 nm; (J) L929 UN I0-65 nm.

Abbreviations: AgNPs, silver nanoparticles; TAm, tannic acid-modified; UN, unmodified.

in vitro. ${ }^{19}$ The scratch area of cells treated with all AgNPs at $5 \mu \mathrm{g} / \mathrm{mL}$ appeared to have a greater number of keratinocytes present within the scratch region when compared to control cells (Figure 3B). However, only TA-modified AgNPs showed a significant increase in cell migration $(p \leq 0.05)$ (Figure 3B).

\section{Dermal inflammatory reaction in mice}

To explore the potential of TA-modified AgNPs for dermal inflammatory reaction, we performed staining with the antigranulocyte receptor-1 (Gr-1) monoclonal antibody (mAb), in ears with TA-modified and unmodified AgNPs applied onto the dorsal part of scarified mouse ears. This antibody binds to Ly6G, which is present on neutrophils, and to Ly6C, which is expressed on neutrophils, and subpopulations of monocytes (Ly6G+ and Ly6C+). Both cell populations actively participate in early inflammation. ${ }^{23}$ In AgNP-treated and untreated ears, we observed strong inflammatory reaction of the thickened epidermis and infiltrating inflammatory cells within dermis (Figure 4A). However, ears treated with TA-modified $13 \mathrm{~nm}$ AgNPs showed the strongest inflammatory reaction with necrosis within the epidermis and strong 
A

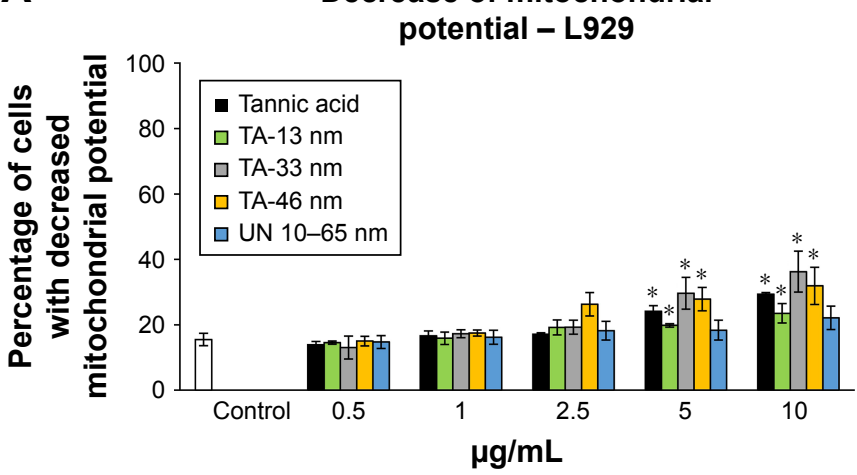

B

Scratch assay - HaCaT

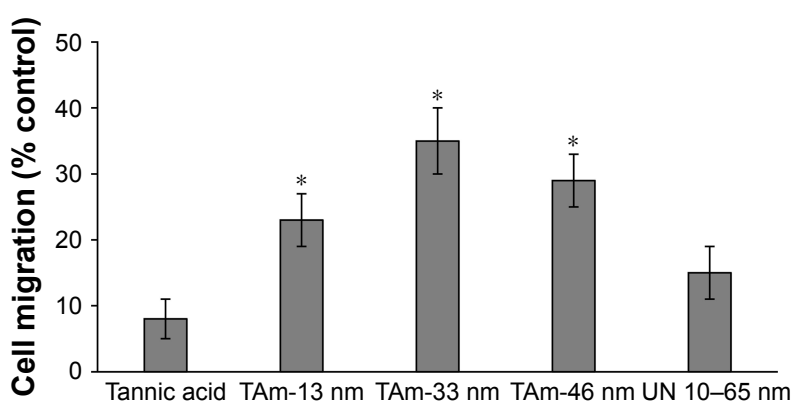

Figure 3 Cytotoxicity assays in L929 cell line (A) and in vitro scratch assay in HaCaT cell line (B) exposed to TAm and unmodified AgNPs.

Notes: (A) L929 cell line was exposed to TAm AgNPs sized 13, 33, $46 \mathrm{~nm}$ and UN 10-65 nm AgNPs at 0.5-10 $\mu$ g/mL for 24 h and subjected to measurement of mitochondrial potential with JC-I. The results are expressed as the percentage of cells with decreased mitochondrial potential. (B) Quantitative analysis of scratch assay in $\mathrm{HaCaT}$ cell line exposed to TAm AgNPs sized 13, 33, $46 \mathrm{~nm}$ and UN 10-65 nm AgNPs at $5 \mu \mathrm{g} / \mathrm{mL}$ for 24 h. Migration of cells is expressed as percentage increase in relation to control, unexposed culture with scratch. Each bar represents the mean from 5 experiments $(\mathrm{N}=5) \pm \mathrm{SEM}$, *Significant differences with $p \leq 0.0 \mathrm{I}$.

Abbreviations: AgNPs, silver nanoparticles; JC-I, IH-benzimidazolium, 5,6-dichloro-2-[3-(5,6-dichloro-I,3-diethyl-I,3-dihydro-2H-benzimidazol-2-ylidene)-I-propenyl]I,3-diethyl-, iodide; TAm, tannic acid-modified; SEM, standard error of the mean; UN, unmodified.

involvement of dermis (Figure 4A). The ears treated with TA-modified 33 and $46 \mathrm{~nm}$ AgNPs and unmodified 10-60 nm AgNPs showed only a small inflammatory reaction within the epidermis and no dermal thickening (Figure 4A). The area occupied by Gr-1+ cells was the biggest in the group of TA-modified $13 \mathrm{~nm}$ AgNP-treated ears in comparison to other groups ( $p=0.001)$ (Figure 4B). To assess activation of the local immune system, we stimulated lymphocytes isolated from the auricular lymph nodes with concanavalin A and measured cell proliferation after $72 \mathrm{~h}$ (Figure 4C). The lymphocytes isolated from mice treated with the irritating citral solution showed the strongest proliferative response (Figure 4C). Treatment with modified or unmodified AgNPs induced significantly lower proliferative response in comparison to citral ( $p \leq 0.001$ ) (Figure 4C). Of all TA-modified AgNPs, the smallest $13 \mathrm{~nm}$ AgNPs showed the highest induction of proliferation ( $p \leq 0.05$ ) (Figure $4 C$ ).

\section{TA-modified 33 and $46 \mathrm{~nm}$ AgNPs improve wound healing}

Wound closure was observed in all treatment groups within 14 days. All tested animals formed scabs at the wound site, which lasted for several days and left residual lesions on the skin tissue after they fell off. Wound closure was clearly observed at day 6 in all experimental groups, except for TA-modified $13 \mathrm{~nm}$ AgNPs, as shown in Figures 5 and 6. The TA-modified $13 \mathrm{~nm}$ AgNPs group also showed a delayed wound closure at day 14 (Figures 5A and 6). The TA-modified 33 and $46 \mathrm{~nm}$ AgNP groups showed an improvement in the wound closure at days 6 and 14 as well as better epithelialization at all tested days in comparison to the control group ( $p \leq 0.05$ ) (Figures $5 \mathrm{~A}$ and 6). In contrast, TA significantly increased epithelial sheet thickness only at day $3(p=0.05)$ (Figures $5 \mathrm{~A}$ and 6 ).

Table 2 Percentage of apoptotic and necrotic mouse 2929 fibroblasts at $24 \mathrm{~h}$ after exposure to TAm I3, 33, $46 \mathrm{~nm} \mathrm{AgNPs}$ and UN 10-65 nm AgNPs at I, 5 and $10 \mu \mathrm{g} / \mathrm{mL}$

\begin{tabular}{|c|c|c|c|c|c|c|}
\hline & Control & TAm- I3 nm & TAm-33 nm & TAm-46 nm & UN I0-65 nm & Tannic acid \\
\hline \multicolumn{7}{|c|}{ Percentage of L929 apoptotic cells } \\
\hline $\mathrm{I} \mu \mathrm{g} / \mathrm{mL}$ & $8.21 \pm 1.25$ & $8.03 \pm 0.96$ & $7.04 \pm 0.53$ & $7.28 \pm 1.28$ & $7.93 \pm 0.57$ & $7.1 \pm 0.71$ \\
\hline $5 \mu \mathrm{g} / \mathrm{mL}$ & & $11.52 \pm 0.26 *$ & $9.3 \pm 1.68$ & $7.18 \pm 1.07$ & $7.96 \pm 0.41$ & $7.2 \pm 0.28$ \\
\hline $10 \mu \mathrm{g} / \mathrm{mL}$ & & $13.49 \pm 2.03 *$ & $|0.76 \pm| .5 \mid$ & $7.6 \pm 0.78$ & $9.09 \pm 2.17$ & $8 \pm 1.99$ \\
\hline \multicolumn{7}{|c|}{ Percentage of L929 necrotic cells } \\
\hline $\mathrm{I} \mu \mathrm{g} / \mathrm{mL}$ & $0.83 \pm 0.21$ & $0.68 \pm 0.3$ & $0.91 \pm 0.19$ & $0.64 \pm 0.09$ & $0.66 \pm 0.03$ & $0.56 \pm 0.03$ \\
\hline $5 \mu \mathrm{g} / \mathrm{mL}$ & & $0.83 \pm 0.07$ & $0.91 \pm 0.19$ & $0.89 \pm 0.08$ & $0.8 \pm 0.03$ & $0.7 \pm 0.02$ \\
\hline $10 \mu \mathrm{g} / \mathrm{mL}$ & & $1.43 \pm 0.06 *$ & $1.35 \pm 0.12 *$ & $0.64 \pm 0.02$ & $1.08 \pm 0.112$ & $0.77 \pm 0.07$ \\
\hline
\end{tabular}

Notes: Apoptotic cells were defined as annexin $\mathrm{V}(+) /$ propidium iodide(-) cells, while necrotic cells are annexin $\mathrm{V}(-) /$ propidium iodide $(+)$. All results represent mean percentage from 3 separate experiments \pm SEM. *Represents significant differences $(p \leq 0.05)$.

Abbreviations: AgNPs, silver nanoparticles; TAm, tannic acid-modified; SEM, standard error of the mean; UN, unmodified. 
A
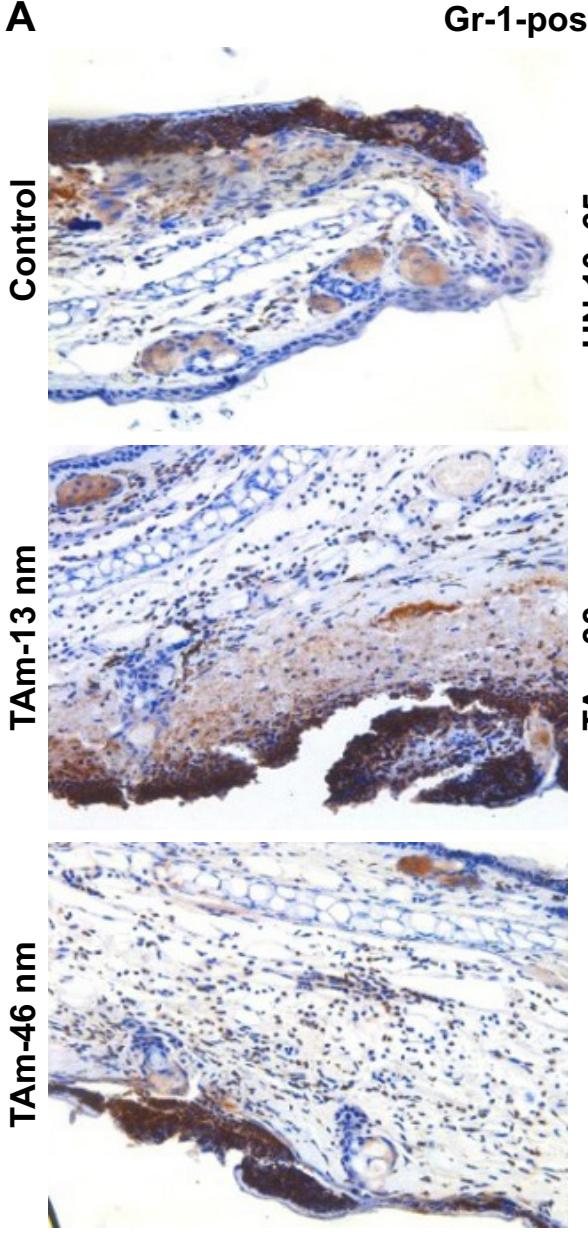

C

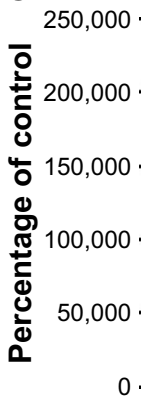

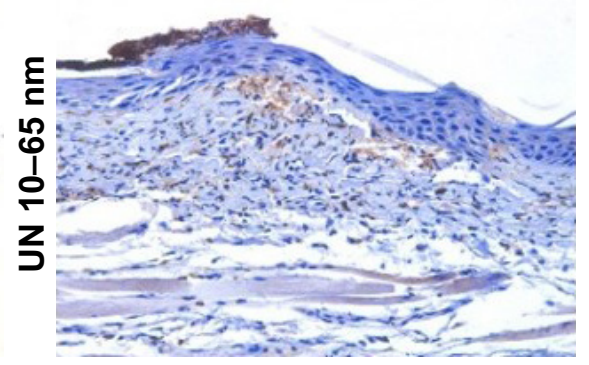

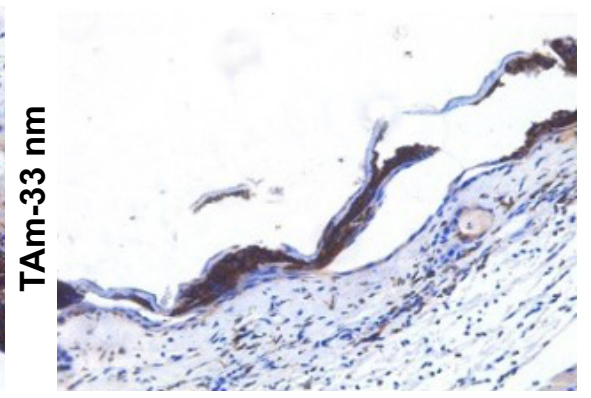

B

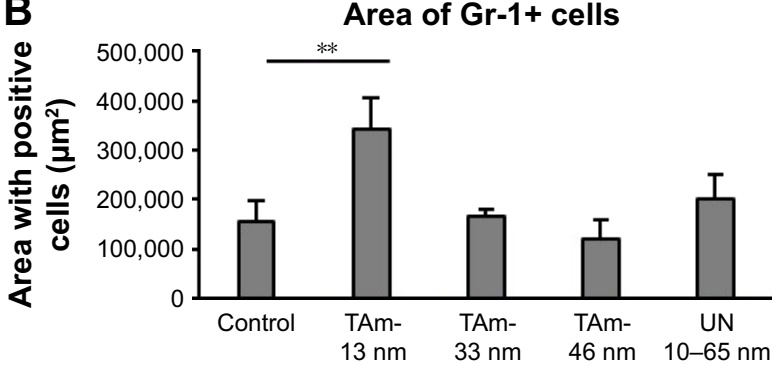

Proliferative response
Area of $\mathrm{Gr}-1+$ cells

(1) 

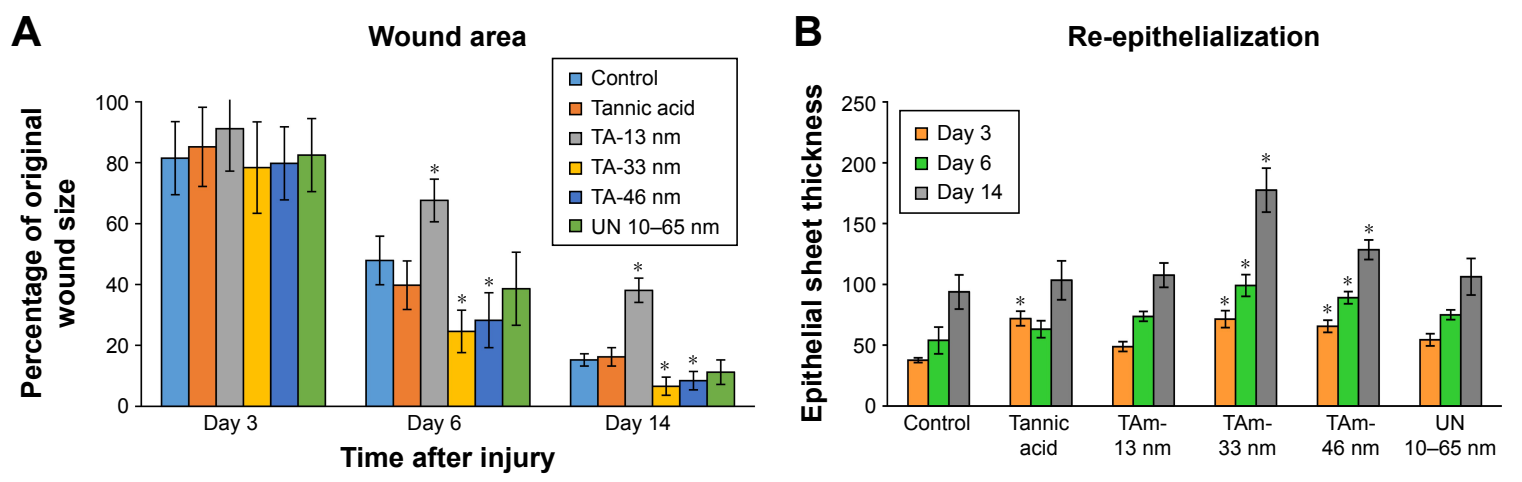

Figure 5 TA AgNPs improve healing in a mouse wound model.

Notes: Silver nanoparticles (TAm TAgNPs sized 13, 33, $46 \mathrm{~nm}$ and UN 10-65 nm AgNPs) or tannic acid were applied at $5 \mu \mathrm{g} / \mathrm{mL}$ in saline, and the wounds were subjected to further tests at 3, 6 and 14 days from injury. Each bar represents the mean from 5 animals $\pm S E M(N=5)$. (A) Percentage of the original wound size. * $p \leq 0.05$ versus untreated control. (B) Re-epithelialization, expressed as the epithelial sheet thickness in micrometers measured in hematoxylin-eosin stained tissue sections at respective days after injury. ${ }^{*} p \leq 0.05$ versus untreated control.

Abbreviations: AgNPs, silver nanoparticles; SEM, standard error of the mean; TAm, tannic acid-modified; UN, unmodified.

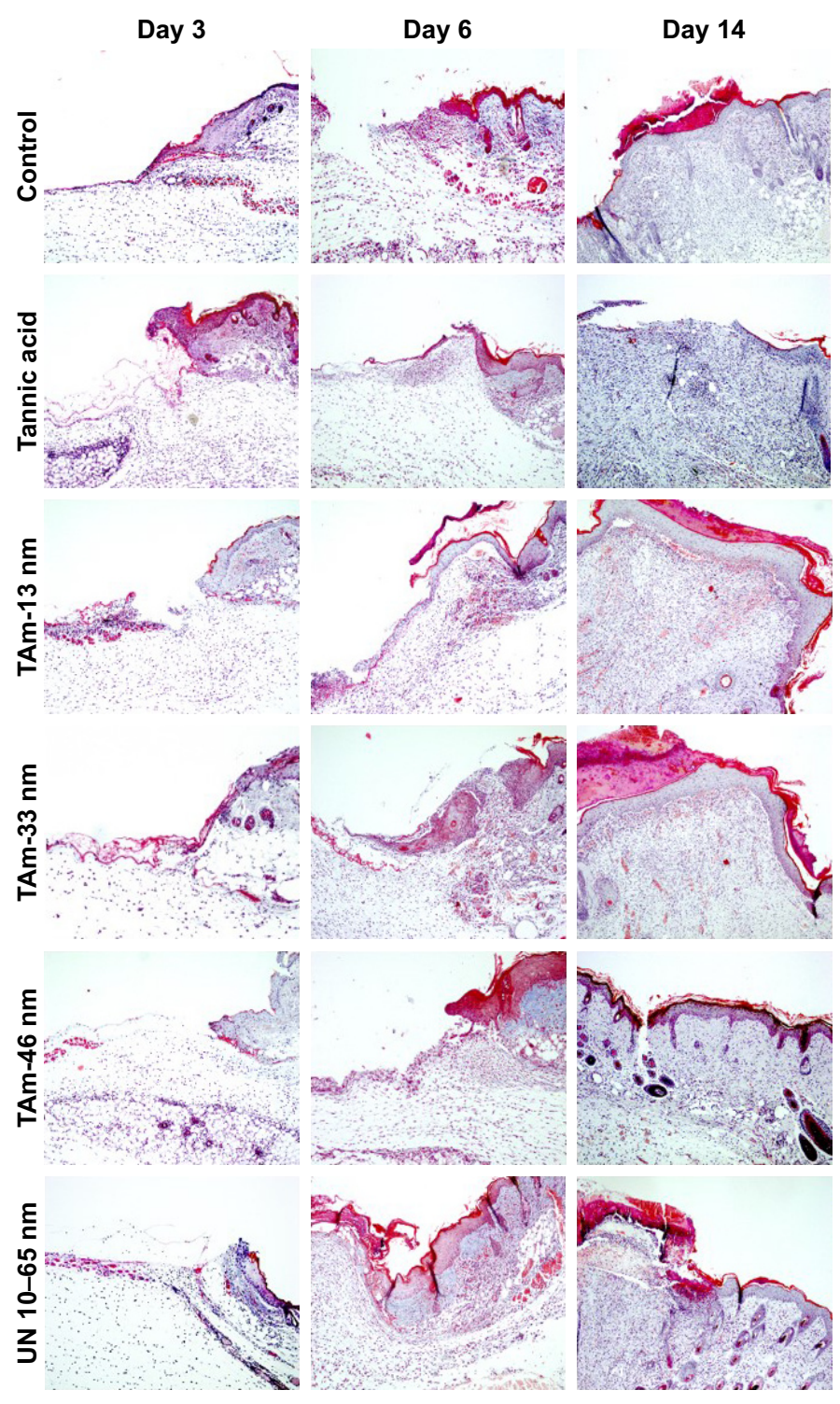

Figure 6 General morphology of wound after treatment with TA and unmodified AgNPs.

Notes: Representative microphotographs of the tri-chrome Masson-stained wound sections at days 3, 6 and I4 postinjury. Silver nanoparticles (TAm AgNPs sized I3, 33 and $46 \mathrm{~nm}$ and UN 10-65 nm AgNPs) or tannic acid were applied at $5 \mu \mathrm{g} / \mathrm{mL}$ in saline. Magnification $400 \times$.

Abbreviations: AgNPs, silver nanoparticles; TAm, tannic acid-modified; UN, unmodified. 
comparison to other groups (Figure 6). The inflammatory cells in the TA-modified 33 and 46 nm AgNP groups disappeared more quickly, and the formation of hair follicles was observed (Figure 6). Interestingly, all AgNP groups showed an increased number of new vessels in the overall appearance of the wound (Figures 6 and 7A).

Formation of new vessels was evaluated by counting the number of new vessels per field (Figure 7A). Wounds treated with all tested AgNPs and TA at day 3 after wounding showed significantly increased number of vessels in comparison to control ( $p \leq 0.05$ ) (Figure 7A). Later during healing, all AgNP-treated wounds showed significantly increased number of blood vessels at day 6 ( $p \leq 0.05$ ) (Figure 7A). However, the number of new vessels at day 14 in wounds subjected to TA-modified 33, $46 \mathrm{~nm}$ AgNPs and unmodified $10-65 \mathrm{~nm}$ AgNPs were significantly decreased in comparison to control wounds ( $p \leq 0.05$ ) (Figure 7A).

To evaluate inflammation in wounds, the number of neutrophils and macrophages per field was calculated (Figure 7B and C). In the TA-modified $13 \mathrm{~nm}$ AgNP group, the neutrophil and macrophage content in the wound tissue was significantly increased during the whole period of healing $(p \leq 0.05$ ) (Figure 7B and C). In the unmodified 10-65 nm group, both neutrophil and macrophage numbers were significantly increased at days 6 and 14 after wounding ( $p \leq 0.05$ ) (Figure 7B and C). The wounds treated with TA-modified 33 and $46 \mathrm{~nm}$ AgNPs showed an increased number of macrophages at day 14 ( $p \leq 0.05$ ) (Figure 7B and C), while for $33 \mathrm{~nm}$ AgNPs, the number of neutrophils was significantly decreased at day $14(p=0.035)$ (Figure 7B).

The presence of AgNPs within the wound was found in all tested groups. AgNPs were found not only in the wound bed at day 3 but also within the inflammatory reaction and extracellular matrix (Figure 8). Neutrophils clearly phagocytized AgNPs. Interestingly, nanoparticles were also localized within myofibroblasts responsible for wound contraction (Figure 8). Later during the tissue repair phase (day 14), we found AgNPs within the granulation tissue, both as intracellular and extracellular deposits. Nanoparticles were often localized in the areas surrounding new hair follicles (Figure 8).
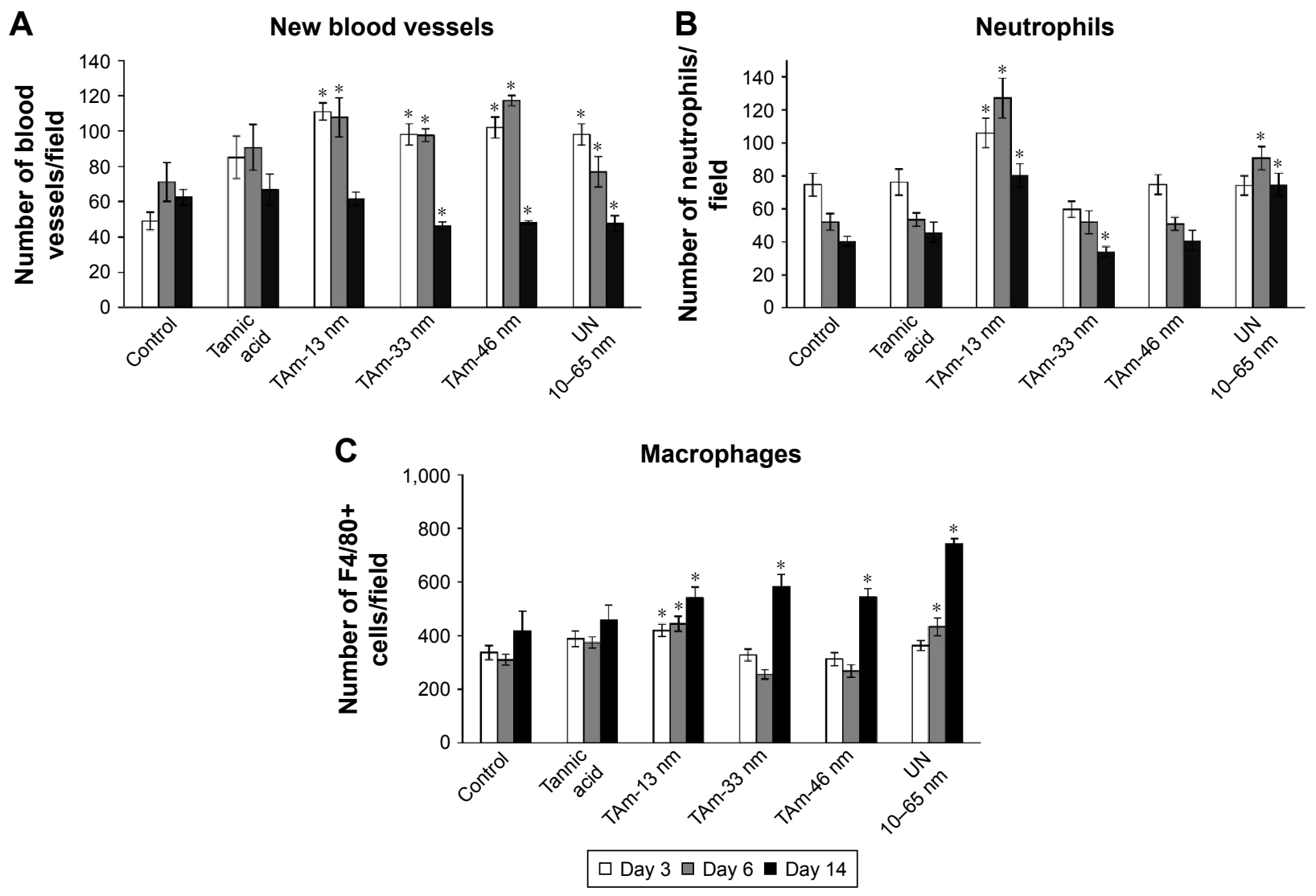

Figure 7 Formation of new vessels and inflammatory infiltration in wounds subjected to treatment with TAm and unmodified AgNPs.

Notes: Wounds were collected at days 3,6 and I4 from injury and analyzed with the microscopic techniques. (A) Number of new vessels per field in the skin sections subjected to tri-chrome Masson's staining (magnification 400X). (B) Number of neutrophils per field in the skin sections subjected to hematoxylin-eosin staining (magnification $400 \times$ ). (C) Number of F4/80+ cells (macrophages) per field in the skin sections subjected to immunohistochemical staining with anti-F4/80 antibody (magnification $400 \times$ ). Each bar represents the mean from 5 animals \pm SEM $(N=5)$. ${ }^{*} \leq 0.05$ versus untreated control.

Abbreviations: AgNPs, silver nanoparticles; SEM, standard error of the mean; TAm, tannic acid-modified; UN, unmodified. 


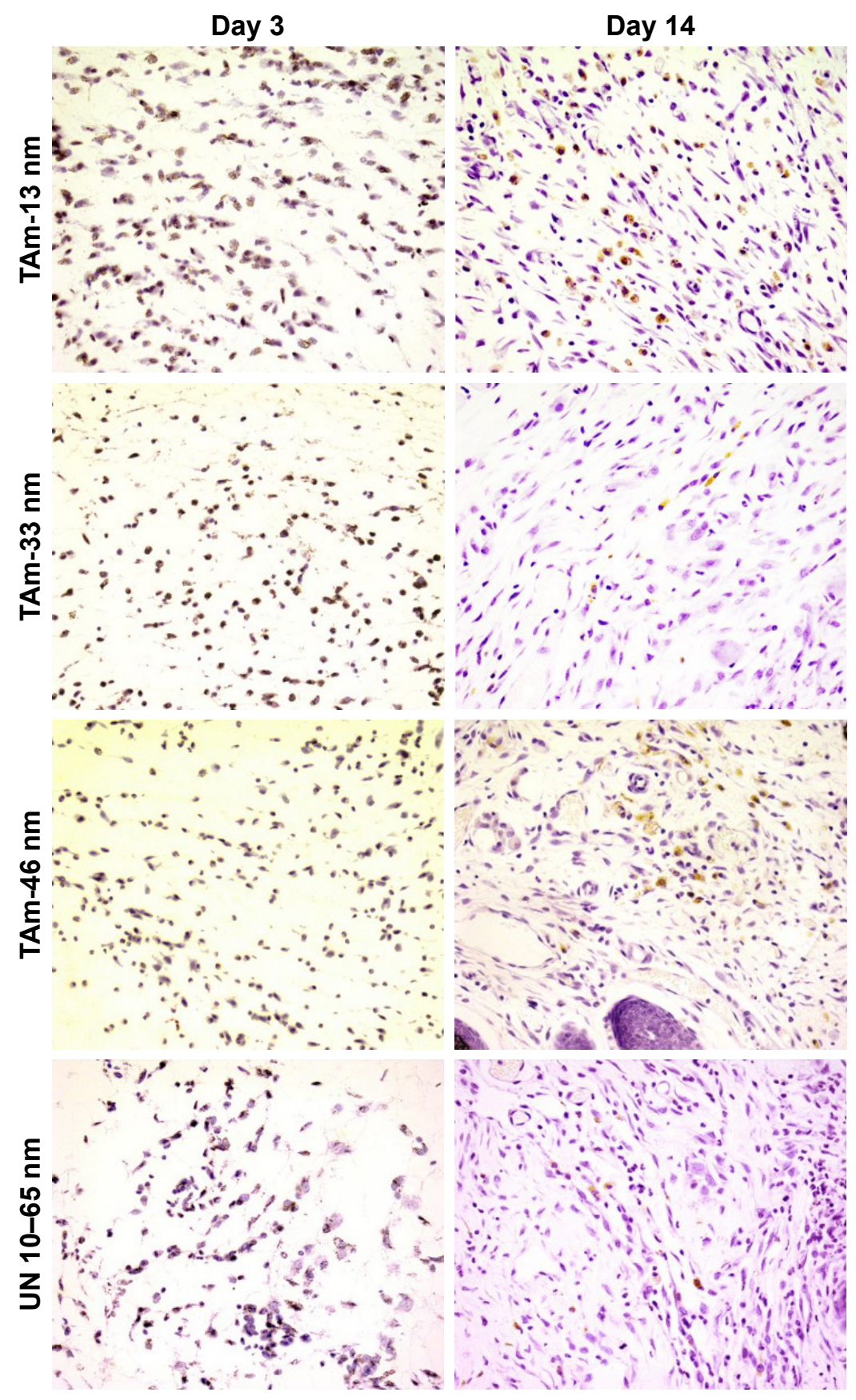

Figure 8 Silver nanoparticles detected in wounds treated with TA and unmodified AgNPs.

Notes: Representative microphotographs of the hematoxylin-stained wound sections at days 3 and 14 postinjury. Magnification 600×.

Abbreviations: AgNPs, silver nanoparticles; TAm, tannic acid-modified; UN, unmodified.

\section{TA-modified AgNPs modulate expression of cytokines in wounds}

mRNA levels of TNF- $\alpha$, TGF- $\beta 1$, IL- $1 \beta$, VEGF- $\alpha$ and PDGF- $\beta$ were measured by qRT-PCR (Figure 9). In general, mRNA expressions of TNF- $\alpha$, TGF- $\beta 1$, VEGF- $\alpha$ and PDGF- $\beta$ were significantly increased in all AgNP groups at day 3 of wound repair in comparison to control wounds $(p \leq 0.05)$ (Figure 9). At day 6 , mRNA levels of PDGF- $\beta$ were significantly increased in all tested groups in comparison to the control group. Levels of mRNA of IL-1 $\beta$ were significantly increased at days 6 and 14 postinjury in wounds treated with TA, while unmodified 10-65 nm significantly increased mRNA of IL-1 $\beta$ at all tested time points in comparison to the control group ( $p \leq 0.05$ ) (Figure 9). TA-modified AgNPs upregulated IL-1 $\beta$ mRNA at day 3 from wounding, while TA-modified 13 and $33 \mathrm{~nm}$ AgNPs upregulated IL-1 $\beta$ mRNA 
A

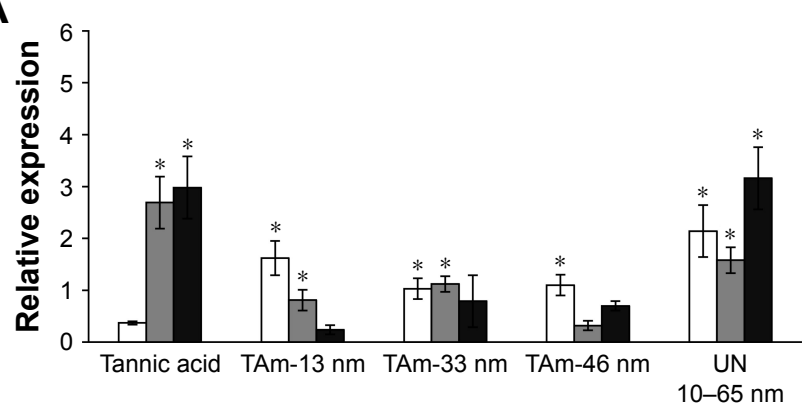

C

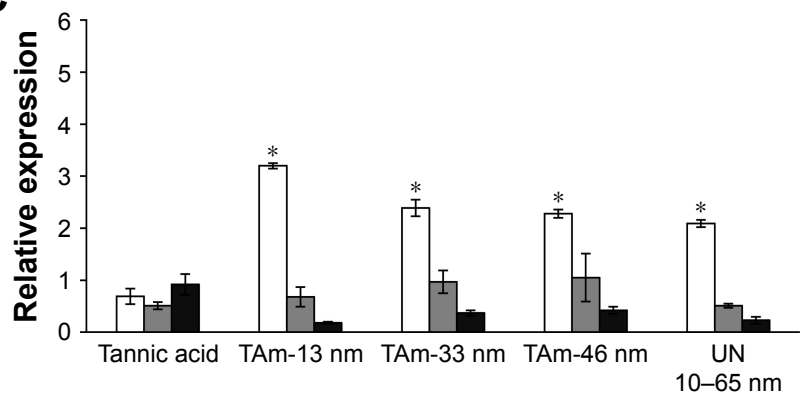

B

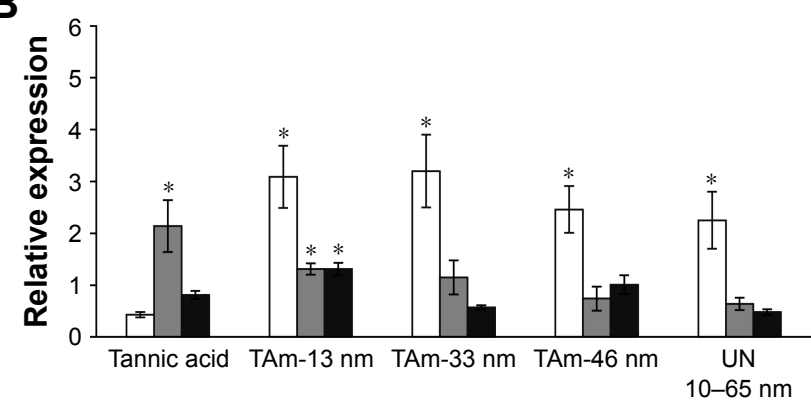

D

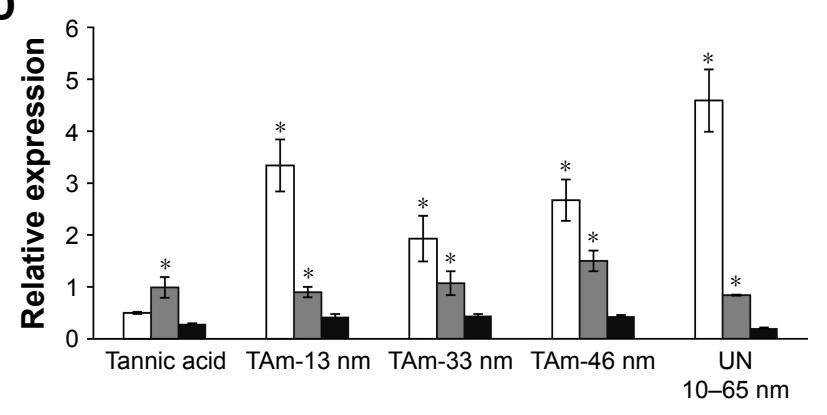

$\mathbf{E}$

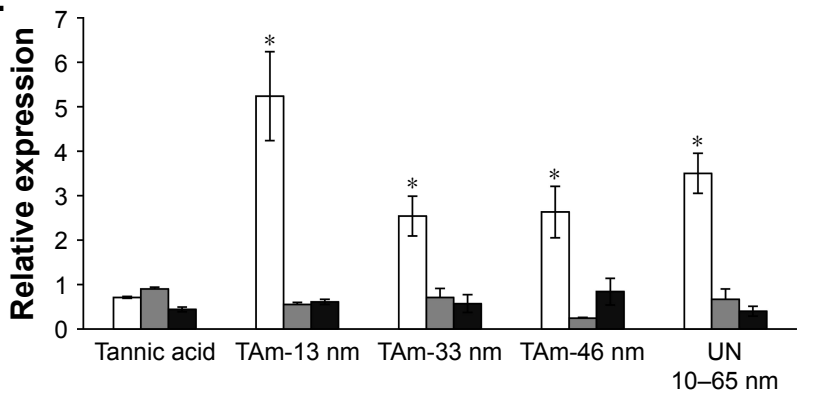

$\square$ Day $3 \quad \square$ Day $6 \quad$ Day 14

Figure 9 Cytokine expression changes in wounds subjected to treatment with TAm and unmodified AgNPs at days 3, 6 and I4 from injury.

Notes: mRNA levels of (A) IL-I $\beta$, (B) TNF- $\alpha$, (C) VEGF- $\alpha$, (D) PDGF- $\beta$, and (E) TGF- $\beta$ I are expressed as expression relative to control on the basis of the $2 \Delta^{\Delta C t}$ method. mRNA levels were counted from 3 PCR reactions for each sample. $N=3$. $* p \leq 0.05$ versus untreated control.

Abbreviations: AgNPs, silver nanoparticles; IL, interleukin; PCR, polymerase chain reaction; PDGF- $\beta$, platelet-derived growth factor- $\beta$; TAm, tannic acid-modified; TGF- $\beta$ I, transforming growth factor- $\beta$ I; TNF- $\alpha$, tumor necrosis factor- $\alpha$; UN, unmodified; VEGF- $\alpha$, vascular endothelial growth factor- $\alpha$.

at day 6 ( $p \leq 0.05$ ) (Figure 9). The highest level of mRNA of TNF- $\alpha$ was observed at days 6 and 14 in wounds treated with TA-modified $13 \mathrm{~nm}$ AgNPs ( $p \leq 0.05$ ) (Figure 9).

\section{Discussion}

Wound healing remains a challenging clinical problem, especially with chronic wounds or unpredictable complications. Wound dressings containing AgNPs can effectively protect an injury from bacterial infection and promote tissue regeneration during the wound healing process. ${ }^{9,10}$ Plantbased products have been used to treat wounds for centuries due to their antioxidant, anti-inflammatory and antimicrobial effects. TA has been shown to stabilize collagen and elastin in the extracellular matrix. This is achieved by inhibiting MMP collagenases while enhancing collagen cross-linking. ${ }^{24,25}$ Additionally, TA inhibits $S$. aureus, $P$. aeruginos $a$ and $E$. coli biofilm formation in multiple biofilm models. ${ }^{26-28}$ Bacterial infection is one of the most serious complications impairing wound healing and tissue regeneration, which may lead to prolonged inflammatory responses, and hence it delays wound recovery. Here, we showed that AgNPs modified with TA inhibited bacterial growth more effectively than TA-modified or unmodified AgNPs (Table 1). Inhibition of bacterial growth was size-dependent (Table 1) with the smallest AgNPs showing the strongest antibacterial activity toward E. coli, while higher sizes of TA-modified AgNPs showed better inhibitory activity toward S. aureus. The latter microorganism is the most common bacteria responsible 
for wound infection. ${ }^{29}$ These results are in accordance with other studies showing size-related antibacterial effects of AgNPs. ${ }^{30,31}$ The small AgNPs show better inhibitory properties owing to the larger surface to volume ratio as compared to larger spherical AgNPs. The antimicrobial properties of AgNPs are attributed to direct interaction of nanoparticles with bacteria membrane and intracellular proteins as well as to the presence of biocidal ionic silver released from nanoparticle surfaces. ${ }^{30-32}$ Although TA does not inhibit bacterial growth, the presence of TA on the particles' surface helps to increase interaction with the bacteria, since unmodified nanoparticles showed much lower MIC values (Table 1).

We have previously reported that TA-modified AgNPs show little cytotoxicity to both mouse and human keratinocytes in vitro, but an increased toxicity was found in mouse monocytes, which showed efficient internalization of TA-modified AgNPs. ${ }^{18,19}$ Furthermore, toxicity was also size dependent with TA-modified AgNPs sized $<20 \mathrm{~nm}$ inducing more cytotoxicity and inflammatory reaction than TA-modified AgNPs $>20 \mathrm{~nm} .{ }^{18,19}$ TA-modified AgNPs showed little toxicity to L929 fibroblasts, and this was concentration-dependent and can be accounted for by the small internalization of nanoparticles (Figure 2). Interestingly, TA-modified AgNPs altered mitochondrial functionality in murine fibroblasts, but this did not seem to lead to cell death (Figure 3A and Table 2). Similar results were shown by Rigo et $\mathrm{al}^{33}$ for $10-15 \mathrm{~nm}$ AgNPs in human fibroblasts.

Fibroblasts play an important role in the wound healing process, by synthesizing and secreting skin collagens; newly formed collagens can fill tissue defects, provide a scaffold for the migration of epidermal cells and regulate cell migration and proliferation. ${ }^{34}$ Nanosilver has been shown to increase wound closure through the promotion of proliferation and migration of keratinocytes and can drive differentiation of fibroblasts into myofibroblasts, thereby promoting wound contraction. ${ }^{35,36}$ Here, the therapeutic efficacy of TA-modified AgNPs in wound healing was assessed using the scratch assay as an in vitro model system and the incisional wound model in mice. Our results from the in vitro model show that TA-modified AgNPs increase HaCaT keratinocyte migration above that observed in control cultures, while TA-modified and unmodified AgNPs increased migration insignificantly (Figure 3B). These results are in contrast to the study by Zanette et al, ${ }^{37}$ showing that a relatively short time of contact with AgNPs causes a long-lasting inhibition of cell growth in HaCaT keratinocytes, not associated with consistent AgNPs' internalization. When applying nanoparticles in the mouse incisional wound model we observed different morphological changes during the inflammation and re-epithelialization phase, depending on the size of TA-modified AgNPs. A faster wound closure, increased re-epithelialization and an increased number of myofibroblasts were observed in mice treated with TA-modified 33 and 46 nm AgNPs as compared with control mice. However, TA-modified $13 \mathrm{~nm}$ AgNPs showed delayed wound healing even at the proliferation and remodeling phase. We have not observed better wound healing with uncoated AgNPs. Other authors showed that not only uncoated AgNPs sized 5-15 nm but also those with a diameter of $\sim 20 \mathrm{~nm}$ accelerated re-epithelialization, enhanced migration of fibroblasts and reduced neutrophil and macrophage infiltration at the wound site in rodent models. ${ }^{36,38,39}$

Histological evaluations revealed that TA-modified AgNPs sized $13 \mathrm{~nm}$, and to a lesser degree, 10-65 nm unmodified AgNPs, maintained neutrophil infiltration at the wound site up to 14 days. In contrast, TA-modified $33 \mathrm{~nm}$ AgNPs significantly accelerated neutrophil disappearance during the remodeling phase. In common experimental models using healthy mice, neutrophil accumulation peaks around day 1 and returns to uninjured levels by days 5-10 after skin wounding. ${ }^{40}$ Neutrophils act as the first-line defense against microbial invasion and foreign debris, which is cleared by phagocytosis. However, the abundance of neutrophils may also lead to the reduced levels of growth factors and production of destructive radical oxygen species and a further delay in healing. ${ }^{40,41}$ This was actually observed here for TA-modified $13 \mathrm{~nm}$ AgNPs. Additionally, application of TA-modified $13 \mathrm{~nm}$ AgNPs onto the stratified ear skin in the LLNA test also led to the local irritation and inflammation, as shown by the presence of Gr-1-positive cells, representing neutrophils and inflammatory monocytes (Figure 4). This shows that nanoparticle size can strongly influence its pro- or anti-inflammatory potential. We have previously shown that TA-modified $13 \mathrm{~nm}$ AgNPs are more toxic to mouse monocytes than TA-modified AgNPs of higher sizes. ${ }^{18,19}$ We can therefore conclude that the increased inflammatory reaction observed in wounds exposed to TA-modified $13 \mathrm{~nm}$ AgNPs may result from the toxic reaction induced in phagocytizing neutrophils and inflammatory monocytes. Monocytes/ macrophages of the inflammatory phase appear to orchestrate the transition to the proliferative phase of healing. Depletion of monocytes/macrophages during the inflammatory phase reduces granulation tissue formation and cell proliferation in mouse skin wounds. ${ }^{40}$ In this study, TA-modified $13 \mathrm{~nm}$ AgNPs maintained a high number of macrophages within the wound during all tested periods, while unmodified AgNPs 
induced accumulation of macrophages in the late phase of wound healing. Interestingly, both TA-modified 33 and $46 \mathrm{~nm}$ AgNPs maintained a high number of macrophages later during healing. This accumulation of macrophages may result from the presence of nanoparticles long after wounding, as we found AgNPs also within the dermis, mostly extracellularly (Figure 8). Rigo et $\mathrm{al}^{33}$ tested for the presence of nanoparticles in human burn wound treated with Acticoat ${ }^{\mathrm{TM}}$ Flex 3 containing AgNPs. The healed skin at day 7 showed a great number of agglomerates of nanoparticles in the upper part of the dermis, and these agglomerates were detected even at 17-days post-burning. ${ }^{33}$ Therefore, AgNPs can affect the wound also at later phases - such as remodeling due to their constant presence in the wound.

All stages of the wound-healing process are regulated by different growth factors, chemokines and cytokines. ${ }^{42}$ Pro-inflammatory cytokines produced by macrophages such as TNF- $\alpha$ and IL-1 $\beta$ can protect against potential invasion of various microorganisms and help to promote proliferative response. ${ }^{42,43}$ However, persistent inflammatory response after wounding delays healing and increases complications. In this study, TA-modified AgNPs showed an advantageous profile of IL- $1 \beta$ and TNF- $\alpha$ production when compared to control, TA-modified and unmodified AgNPs. Both IL-1 $\beta$ and TNF- $\alpha$ were upregulated early after wounding (up to day 3, except for $13 \mathrm{~nm}$ TA-modified AgNPs) and decreased at later times. Previous reports showed that AgNPs were capable of inhibiting the inflammatory reaction to promote wound healing. ${ }^{39,44} \mathrm{We}$ also showed previously that TA-modified but not unmodified AgNPs downregulated inflammatory response in human keratinocytes subjected to TNF- $\alpha$ and LPS. ${ }^{19}$ Apart from creating a pro-inflammatory microenvironment, macrophages also release growth factors including VEGF- $\alpha$, TGF-1 $\beta$ and PDGF- $\beta$, which promote keratinocyte and fibroblast migration, proliferation and

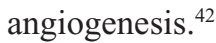

Here, we found that both TA-modified and unmodified AgNPs induced expression of VEGF- $\alpha$, TGF- $1 \beta$ and PDGF early during wound healing (proliferative phase), but this effect could be contributed to the AgNPs rather than TA modification and did not depend on the AgNPs' size. Other authors also showed that AgNPs act efficiently during the early stages of wound healing by upregulating the expression levels of cytokines associated with the TGF-1 $\beta / \mathrm{Smad}$ signaling pathway, such as TGF $\beta 1 .^{45,46}$ TGF $\beta 1$ plays an important role in almost all stages of wound healing and scar formation. ${ }^{46}$ Gurunathan et $\mathrm{al}^{47}$ have demonstrated that AgNPs inhibited VEGF-induced cell proliferation, migration and capillary-like tube formation of bovine retinal endothelial cells as well as effectively inhibited formation of new blood microvessels induced by VEGF. Here, we observed an opposite effect, with both TA-modified and unmodified AgNPs inducing VEGF upregulation early during wound healing.

Despite the fact that all sizes of TA-modified AgNPs induced upregulation of cytokines involved in wound healing, small-sized TA-modified AgNPs can elicit strong inflammatory response not only during wound healing but also when applied to stratified skin.

\section{Conclusion}

Taking into account not only the ability of AgNPs to penetrate skin and interact with the skin immune system but also the immunomodulatory effects of TA, we can assume that the synthesis of AgNPs with TA allows preparation of a new type of nanomaterials. TA-modified AgNPs sized $>26 \mathrm{~nm}$ not only show a good biocompatibility, an effective antibacterial activity and anti-inflammatory properties but can also efficiently accelerate wound healing. Therefore, TA-modified AgNPs can be potentially used as an ideal wound dressing for cutaneous wounds.

\section{Acknowledgments}

This work was supported by the National Science Centre Poland grant no 2014/13/B/NZ5/01356. We would like to thank Aleksandra Fruba and Karolina Bien for excellent technical help.

\section{Author contributions}

Piotr Orlowski made substantial contributions to conception and design, acquisition of data, analysis and interpretation of data. Magdalena Zmigrodzka made substantial contributions to acquisition of data and analysis of data. Emilia Tomaszewska made substantial contributions to acquisition of data and analysis of data. Katarzyna Ranoszek-Soliwoda made substantial contributions to acquisition of data and analysis of data. Malgorzata Antos-Bielska made substantial contributions to acquisition of data. Janusz Szemraj made substantial contributions to acquisition of data. Grzegorz Celichowski made substantial contributions to design, and analysis and interpretation of data. Jaroslaw Grobelny made substantial contributions to design, and analysis and interpretation of data. Malgorzata Krzyzowska made substantial contributions to conception and design, interpretation of data, drafting the article, agreement to be accountable for all aspects of the work in ensuring that questions related to the accuracy of any part of the work are appropriately investigated and resolved. 
All authors contributed toward data analysis, drafting and critically revising the paper and agree to be accountable for all aspects of the work.

\section{Disclosure}

The authors report no conflicts of interest in this work.

\section{References}

1. Schreml S, Szeimies RM, Prantl L, Landthaler M, Babilas P. Wound healing in the 21st century. J Am Acad Dermatol. 2010;63(5):866-881.

2. Martin $P$, Nunan R. Cellular and molecular mechanisms of repair in acute and chronic wound healing. Br J Dermatol. 2015;173(2):370-378.

3. Cho KH, Park JE, Osaka T, Park SG. The study of antimicrobial activity and preservative effects of nanosilver ingredient. Electrochim Acta. 2005;51(5):956-960.

4. Clinton A, Carter T. Chronic wound biofilms: pathogenesis and potential therapies. Lab Med. 2015;46(4):277-284.

5. Sadeghi B, Garmaroudi FS, Hashemi M, et al. Comparison of the antibacterial activity on the nanosilver shapes: nanoparticles, nanorods and nanoplates. Adv Powder Technol. 2012;23(1):22-26.

6. Larese FF, D'Agostin F, Crosera M, et al. Human skin penetration of silver nanoparticles through intact and damaged skin. Toxicology. 2009;255(1-2):33-37.

7. Kim JS, Kuk E, Yu KN, et al. Antimicrobial effects of silver nanoparticles. Nanomedicine. 2007;3(1):95-101.

8. Morones JR, Elechiguerra JL, Camacho A, et al. The bactericidal effect of silver nanoparticles. Nanotechnology. 2005;16(10):2346-2353.

9. Tian J, Wong KK, Ho CM, et al. Topical delivery of silver nanoparticles promotes wound healing. ChemMedChem. 2007;2(1):129-136.

10. Zhang S, Liu X, Wang H, Peng J, Wong KK. Silver nanoparticle-coated suture effectively reduces inflammation and improves mechanical strength at intestinal anastomosis in mice. J Pediatr Surg. 2014;49(4): 606-613.

11. Haslam E. Natural polyphenols (vegetable tannins) as drugs: possible modes of action. J Nat Prod. 1996;59(2):205-215.

12. Akiyama H, Fujii K, Yamasaki O, Oono T, Iwatsuki K. Antibacterial action of several tannins against Staphylococcus aureus. J Antimicrob Chemother. 2001;48(4):487-491.

13. Bakondi E, Bai P, Erdelyi K, Szabo C, Gergely P, Virag L. Cytoprotective effect of gallotannin in oxidatively stressed $\mathrm{HaCaT}$ keratinocytes: the role of poly(ADP-ribose) metabolism. Exp Dermatol. 2004; 13(3):170-178.

14. Fernandez O, Capdevila JZ, Dalla G, Melchor G. Efficacy of Rhizophora mangle aqueous bark extract in the healing of open surgical wounds. Fitoterapia. 2002;73(7-8):564-568.

15. Buzzini P, Arapitsas P, Goretti M, et al. Antimicrobial and antiviral activity of hydrolysable tannins. Mini Rev Med Chem. 2008;8(12): 1179-1187.

16. Ranoszek-Soliwoda K, Tomaszewska E, Socha E, et al. The role of tannic acid and sodium citrate in the synthesis of silver nanoparticles. J Nanopart Res. 2017;19:273.

17. Cataldo F, Ursini O, Angelini G. A green synthesis of colloidal silver nanoparticles and their reaction with ozone. Eur Chem Bull. 2013; 2(10):700-705.

18. Orlowski P, Krzyzowska M, Zdanowski R, et al. Assessment of in vitro cellular responses of monocytes and keratinocytes to tannic acid modified silver nanoparticles. Toxicol In Vitro. 2013;27(6):1798-1808.

19. Orlowski P, Soliwoda K, Tomaszewska E, et al. Toxicity of tannic acid-modified silver nanoparticles in keratinocytes: potential for immunomodulatory applications. Toxicol In Vitro. 2016;35:43-54.

20. Tomaszewska E, Soliwoda K, Kadziola K, et al. Detection limits of DLS and UV-vis spectroscopy in characterization of polydisperse nanoparticles colloids. J Nanomaterials. 2013;2013:313081.
21. Salvioli S, Ardizzoni A, Franceschi C, Cossarizza A. JC-1, but not DiOC6(3) or rhodamine 123, is a reliable fluorescent probe to assess delta psi changes in intact cells: implications for studies on mitochondrial functionality during apoptosis. FEBS Lett. 1997;411(1): 77-82.

22. Liang CC, Park AY, Guan JL. In vitro scratch assay: a convenient and inexpensive method for analysis of cell migration in vitro. Nat Protoc. 2007;2(2):329-333.

23. Sasmono RT, Ehrnsperger A, Cronau SL, et al. Mouse neutrophilic granulocytes express mRNA encoding the macrophage colony-stimulating factor receptor (CSF-1R) as well as many other macrophage-specific transcripts and can transdifferentiate into macrophages in vitro in response to CSF-1. J Leukoc Biol. 2007;82(1):111-123.

24. Zhang H, Zhu SJ, Wang D, Wei YJ, Hu SS. Intramyocardial injection of tannic acid attenuates postinfarction remodeling: a novel approach to stabilize the breaking extracellular matrix. J Thorac Cardiovasc Surg. 2009; 137(1):216-222.

25. Natarajan V, Krithica N, Madhan B, Sehgal PK. Preparation and properties of tannic acid cross-linked collagen scaffold and its application in wound healing. J Biomed Mater Res B Appl Biomater. 2013; 101(4):560-567.

26. Payne DE, Martin NR, Parzych KR, Rickard AH, Underwood A, Boles BR. Tannic acid inhibits Staphylococcus aureus surface colonization in an IsaA-dependent manner. Infect Immun. 2013;81(2): 496-504.

27. Hancock V, Dahl M, Vejborg RM, Klemm P. Dietary plant components ellagic acid and tannic acid inhibit Escherichia coli biofilm formation. J Med Microbiol. 2010;59(pt 4):496-498.

28. Trentin DS, Silva DB, Amaral MW, et al. Tannins possessing bacteriostatic effect impair Pseudomonas aeruginosa adhesion and biofilm formation. PLoS One. 2013;8(6):e66257.

29. Percival SL, Hill KE, Williams DW, Hooper SJ, Thomas DW, Costerton JW. A review of the scientific evidence for biofilms in wounds. Wound Repair Regen. 2012;20(5):647-657.

30. Raza MA, Kanwal Z, Rauf A, Sabri AN, Riaz S, Naseem S. Size- and shape-dependent antibacterial studies of silver nanoparticles synthesized by wet chemical routes. Nanomaterials (Basel). 2016;6(4):74.

31. Zille A, Fernandes MM, Francesko A, et al. Size and aging effects on antimicrobial efficiency of silver nanoparticles coated on polyamide fabrics activated by atmospheric DBD plasma. ACS Appl Mater Interfaces. 2015;7(25):13731-13744.

32. Choi O, Deng KK, Kim NJ, Ross L, Surampalli RY, Hu ZQ. The inhibitory effects of silver nanoparticles, silver ions, and silver chloride colloids on microbial growth. Water Res. 2008;42(12):3066-3074.

33. Rigo C, Ferroni L, Tocco I, et al. Active silver nanoparticles for wound healing. Int J Mol Sci. 2013;14(3):4817-4840.

34. Pastar I, Stojadinovic O, Yin NC, et al. Epithelialization in wound healing: a comprehensive review. Adv Wound Care. 2014;3(7):445-464.

35. Liu X, Lee PY, Ho CM, et al. Silver nanoparticles mediate differential responses in keratinocytes and fibroblasts during skin wound healing. ChemMedChem. 2010;5(3):468-475.

36. Kwan KH, Liu X, To MK, Yeung KW, Ho CM, Wong KK. Modulation of collagen alignment by silver nanoparticles results in better mechanical properties in wound healing. Nanomedicine. 2011;7(4): 497-504.

37. Zanette C, Pelin M, Crosera M, et al. Silver nanoparticles exert a longlasting antiproliferative effect on human keratinocyte HaCaT cell line. Toxicol In Vitro. 2011;25(5):1053-1060.

38. Neibert K, Gopishetty V, Grigoryev A, et al. Wound-healing with mechanically robust and biodegradable hydrogel fibers loaded with silver nanoparticles. Adv Healthc Mater. 2012;1(5):621-630.

39. Wen L, Zeng P, Zhang L, Huang W, Wang H, Chen G. Symbiosis theorydirected green synthesis of silver nanoparticles and their application in infected wound healing. Int J Nanomedicine. 2016;11:2757-2767.

40. Dovi JV, He LK, DiPietro LA. Accelerated wound closure in neutrophildepleted mice. J Leukoc Biol. 2003;73(4):448-455. 
41. Mirza R, DiPietro LA, Koh TJ. Selective and specific macrophage ablation is detrimental to wound healing in mice. Am J Pathol. 2009;175(6): 2454-2462.

42. Werner S, Grose R. Regulation of wound healing by growth factors and cytokines. Physiol Rev. 2003;83(3):835-870.

43. Rodero MP, Khosrotehrani K. Skin wound healing modulation by macrophages. Int J Clin Exp Pathol. 2010;3(7):643-653.

44. Wong KK, Cheung SO, Huang L, et al. Further evidence of the anti-inflammatory effects of silver nanoparticles. ChemMedChem. 2009;4(7):1129-1135.

45. Li CW, Wang Q, Li J, et al. Silver nanoparticles/chitosan oligosaccharide/poly(vinyl alcohol) nanofiber promotes wound healing by activating TGF $\beta 1 /$ Smad signaling pathway. Int J Nanomedicine. 2016; $11: 373-386$.
46. Tang B, Zhu B, Liang Y, et al. Asiaticoside suppresses collagen expression and TGF- $\beta /$ Smad signaling through inducing Smad7 and inhibiting TGF- $\beta$ RI and TGF- $\beta$ RII in keloid fibroblasts. Arch Dermatol Res. 2011;303(8):563-572.

47. Gurunathan S, Lee KJ, Kalishwaralal K, Sheikpranbabu S, Vaidyanathan R, Eom SH. Antiangiogenic properties of silver nanoparticles. Biomaterials. 2009;30(31):6341-6350.
International Journal of Nanomedicine

\section{Publish your work in this journal}

The International Journal of Nanomedicine is an international, peerreviewed journal focusing on the application of nanotechnology in diagnostics, therapeutics, and drug delivery systems throughout the biomedical field. This journal is indexed on PubMed Central, MedLine, CAS, SciSearch $®$, Current Contents $® /$ Clinical Medicine,

\section{Dovepress}

Journal Citation Reports/Science Edition, EMBase, Scopus and the Elsevier Bibliographic databases. The manuscript management system is completely online and includes a very quick and fair peer-review system, which is all easy to use. Visit http://www.dovepress.com/ testimonials.php to read real quotes from published authors.

Submit your manuscript here: http://www.dovepress.com/international-journal-of-nanomedicine-journal 